\title{
Study on Hotel Green Marketing Strategies under Low-carbon Economic Environment
}

\author{
Min Ding \\ School of Business Administration, Nanjing University of Finance and Economics, Nanjing, 210046, China
}

\begin{abstract}
Low-carbon macro-economic environment and competitive microenvironment determine the implementation of hotel green marketing. However, both hotel managers and hotel guests have misunderstanding of low-carbon green products and their price. The hotel cannot balance its relationship with distributors during the hotel low-carbon green marketing process. Promotions are far from enough. Product hierarchical analysis is used to analyze the hotel product, price, place and promotion strategies of green marketing under low-carbon environment. Only the four perspectives are fulfilled can the hotel be a low-carbon green hotel in the real sense, hence, shoulder its due social responsibilities.
\end{abstract}

Keywords-low-carbon economy; low-carbon hotel; green marketing.

\section{INTRODUCTION}

According to the statistics of UNWTO, international tourist arrivals grew by 5\% in 2013[1]. The tourism sector has continued robust growth, fuelling growth and job creation around the world, despite the lingering economic and geopolitical challenges. Therefore, the development of tourism is of great significance to the recovery of economy. However, the characteristic of seeking comfort of mass tourists has incurred great energy consumption, esp. the hotel industry, which has not adapted to the global lowcarbon economy. As one of the largest and most robust industries, the tourism industry should take active measures to adapt to the low-carbon economy trend in order to promote the sound development of the industry.

\section{THE IMPACT OF LOW-CARBON ECONOMIC ENVIRONMENT ON HOTEL GREEN MARKETING}

The macro-economic environment of low-carbon determines it is imperative to implement hotel green marketing. Global warming has endangered the living environment and safety of human being. UNIPCC pointed out that global warming in recent 50 years has been incurred by co2, methane, nitrous oxide emission of human activity. Therefore, it is common sense to lower carbon emission and implement green development. From Kyoto Protocol in 1997, Bali Route in 2007 to the long-term goal to reduce greenhouse gas emission in half by 2050 in G8 Summit, Tokyo 2008, countries all over the world are seeking ways to lower carbon emission actively. In China, the State Council also decides that the internal $\mathrm{Co} 2$ emission will be reduced $40 \%$ or $50 \%$ by 2020 compared with 2005.Accommodations are the main source of carbon emission in tourism industry besides air flight. The implementation of green marketing under such macro environment is the positive response to reduce energy consumption and lower emission as a responsible country. The hotel industry should take environment protection and low emission measures in its operation to build a good public image which is of great significance to shoulder corporate social responsibility.

Microenvironment of competition demands hotel green marketing in order to save and develop.

In recent years, the domestic hotel groups compete closely in order to obtain limited market resources. International hotel groups such as Sheraton, Shangrila, Hilton and Holiday Inn participate in the competition, therefore, the local high-market brand is very passive. Challenged by the close competition home and abroad, the hotel industry has entered a low-profit era. The average profitability of some hotels is even minus. It is of great significance to control the hotel cost so as to save and develop. The core aim of modern hotels is to fulfil the guests and improve efficiencies. There are two means to improve efficiencies: expand operation channels to improve income and reduce cost to save. Cost is a direct and controlled element of hotel operation. When incomes are equalled, cost forms inverse ratio with economic benefits. The successful hotels home and abroad all make their ways to reduce cost. Different hotels, therefore, get different economic effects facing the same market conditions. Energy consumption is a big item of hotel expenditure. Guided by low-carbon concept, hotels implement green marketing to ensure saving energy and reducing emission so as to achieve the aim of thrifty.

\section{EXISTING PROBLEMS OF HOTEL GREEN MARKETING UNDER LOW-CARBON ECONOMIC ENVIRONMENT}

\section{A. The Limited Recognition to Low-carbon Green Products of Hotel Managers and Hotel Guests}

At present, most people have little awareness of lowcarbon and green consumption, who think that green products mean no six little amenities offered by the hotel and the notice of less sheets change. Hotel guests argue that they have spent the money for food, play and enjoyment, therefore, it is common phenomena to waste water, electricity and food during their accommodations. The 
average electricity and water consumption for one square meter in the hotel is more than 10 times that in the family. Many guests are not satisfied with low-carbon and environment protection regulations who regard it is uncomfortable and inconvenient for travelling, and even complain it. The low-carbon green idea hasn't been widely accepted. The shift of consumption habits is a long course. Hotels can take some measures to stimulate the consumption so as to be coordinated with low-carbon green marketing.

\section{B. Wrong Recognition of Low-carbon Green Products Price by Hotel Managers and Guests}

As a profitable organization, the low-carbonization of hotels is a difficult and complicated process. The managers focus on the profitability, however, the preliminary term of hotel low-carbonization and greening demands large sum of capital, which is the biggest obstacle to promote low-carbon hotel. Ordinary consumers may think that low-carbon green products are more expensive than traditional hotel products because of the additional developing knowledge, labour and investment for low-carbon products. All these limited recognition hinder the promotion of low-carbon green products.

\section{Unbalanced Relationship with the Distributor During the Process of Low-carbon Green Marketing}

The hotel hardly cares of its own website and is lack of building ability, which incur the over dependence on the distributor, therefore, the hotel loses its bargain ability.

\section{Few Promotion Policies of Low-carbon Green Products}

As a new product, the hotel should make enough promotions to lead and stimulate consumers. At the same time, the hotel should make use of electronic media for free promotion in the Internet mobile era.

\section{HOTEL GREEN MARKETING STRATEGIES UNDER LOW-CARBON ECONOMIC ENVIRONMENT}

Global low-carbon economic environment provides friendly macro environment for hotel green marketing, under which hotel managers take appropriate marketing measures to ensure business profits as well as the sustainable development of tourism.

\section{A. Product Strategies of Hotel Green Marketing under Low-carbon Economy}

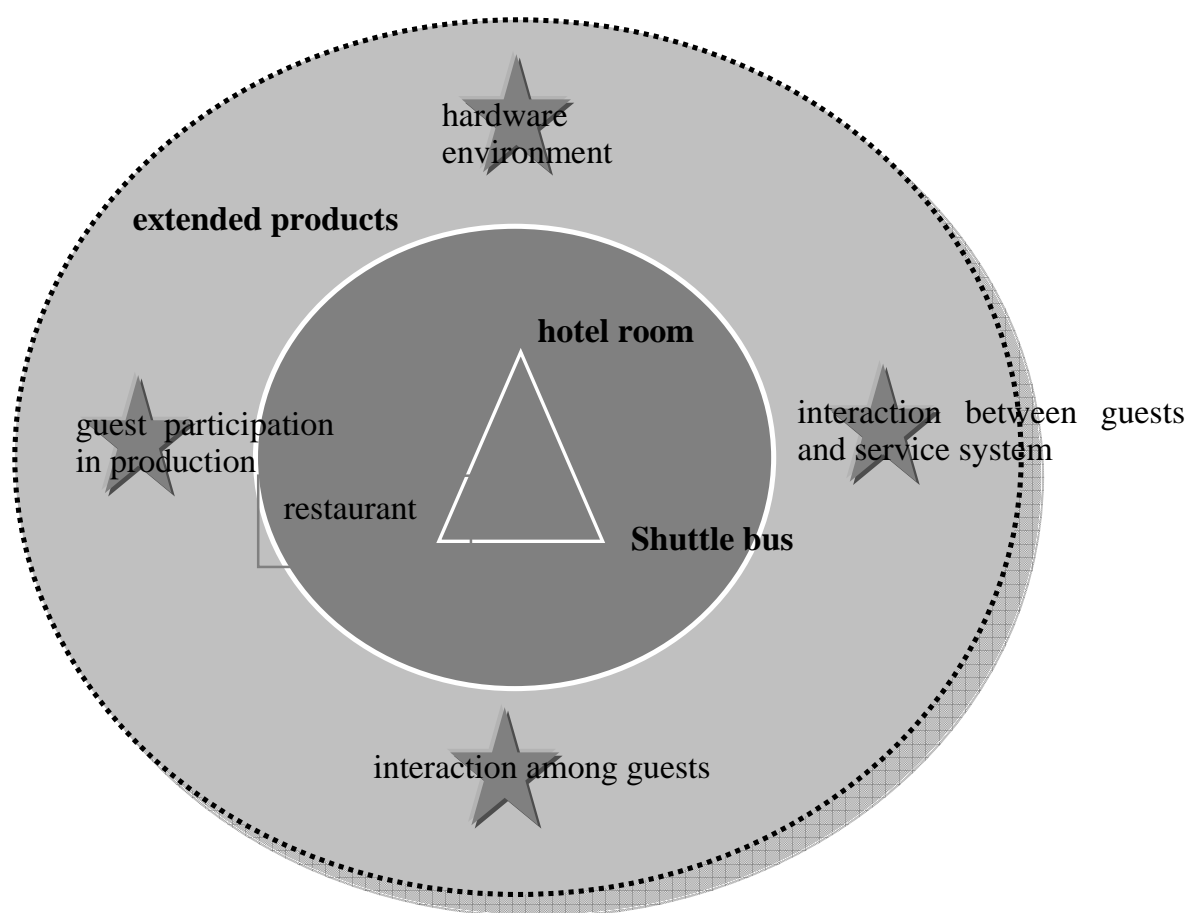

Figure 1. Hierarchical analysis of hotel products

Resource: based on C.Gonroos, "Developing the Service Offering-A Source of Competitive Advange[2]

First and foremost, a whole and complete conception of green products should be comprehended before implementing the product strategies of hotel green marketing under low-carbon economic environment. Second is prospect. Gonroos classifies the product into four levels, which also fits the hotel products. Core product is the basic level of the product, which refers to what the purchaser really wants to buy. The core product of the hotel is the room. Hotel guests should be offered low-carbon green room under low-carbon economic environment, which in strict sense demands all the environmental behaviour involved from design to product supply should meet the needs of low-carbon and environment protection. For example, soap, shampoo and body gel are natural. One-time 
package is not provided but sustainable device. Water can be used to wash the toilet and for shower after filtration. Furniture is made of secondary trees. Also available are recycled paper, cotton ramie linen, no-poison floor and wallpaper, energy-saving light, environment-friendly cleaning products, Secondly, promote the regular energy (coal, petroleum),make full use of recycled energy (solar energy, water energy, wind energy) and develop clean energy. When big energy machine devices are selected to furnish, the decision-maker should be prospective. For example, the boiler can use diesel fuel, liquefied natural gas or gasoline alternatively so the most efficient and environment-protecting fuel can be selected[3]. Such mega energy devices should not only be environment-protecting but also be quality-assuring so they can be used for at least ten to twenty years to avoid waste caused by frequent change of device. Last but not least, a sophisticated computer system should be used to manage the hotel energy consumption. The computer system based on energy saving controls all the lights. So long as the natural light is lower than the set Lux parameter, the computer system can switch the light by the adjuster furnished on light system. On or off is not decided by subjective perception so as to avoid waste. This computer system can not only display the air quality and temperature precisely but also adjust the temperature automatically and release fresh air to ensure the air quality in the room. The comfort of the hotel guests is ensured and at the same time energy consumption is managed[3].

Allocated products are those things or services available when customers use core products. The most important allocated product of the hotel is the restaurant. In order to build low-carbon green restaurant, zero distance purchase is the key for F\&B Department which means the hotel should purchase the food locally produced at most to reduce transport. The hotel can choose its local vegetable base and use green vegetable. Next is the use of natural pigment for cuisine. There is no additive or rare wild animal for cooking. Last but not the least is the green service which is provided to the consumers with the food simultaneously. The service follows the whole producing and consuming process. For example, green food and beverage is recommended to the guests. When the guests order dish, the waiter should help them to order economically, nutritiously and packing service is offered to the guests.

Supportive products are those additional products besides core products, which differentiate them from competitive products. For example, some hotels offer shuttle bus service from the hotel to the airport. From the perspective of product level, supportive products are competitive edges that differentiate them from opponents, which, however, must be offered in professional means to display such advantages and enhance the core competitiveness. Otherwise, they are the burden to the hotel. For example, Hongkong hotels and transport companies cooperate with each other to provide shuttle bus services for guests from hotels to the airport, which on one side reduce the burden of the hotel, on the other side low-carbon operation is implemented by the use of public transport.
Extended products include accessibility (geographical position and opening time), atmosphere (visual, auditory, olfactory and tactile), the interaction between customers and service (participation, consumption and departing), customer participation and customer interaction[4]. One of the important elements of extended products is atmosphere. Hotels should create a low-carbon atmosphere for the guests who are glad to stay in such a low-carbon green hotel paying great attention to environment protection. The atmosphere can be created by visual, auditory, olfactory and tactile elements. The guests stay in such a low-carbon hotel without extra charge, which is the additional benefit for them. This is the important reason for guest repetition.

The development of low-carbon green products is the key and supporting point to implement low-carbon green marketing. Green products with low-carbon idea demands the products to meet special environment protection needs from design to service, which therefore boast such environment edges as energy saving and are beneficial to resource regeneration. After the use of such products, recycling and disposal should be considered.

\section{B. Pricing Strategy of Hotel Green Marketing under Low- carbon Economy}

Price is a sensitive element of the market and pricing is an important policy of marketing. Ordinary consumers think the price of low-carbon green product must be higher than traditional products because of additional knowledge, labour and materials to develop low-carbon products. Generally speaking, at introduction stage, production cost of lowcarbon green products is higher than the same traditional products, however, the uprising of the price is temporary. The cost of low-carbon products will be gradually falling down and go to stable with the innovation and development of resource technique and energy saving led by primitive low-carbon products. Hotel green products guided by lowcarbon idea are the results of energy innovation and energy efficiency with the additional cost is returned back. The production cost of hotel low-carbon green products is sure to fall down gradually with the development of scientific techniques and the perfection of environment measures. On the other side, the idea of price and consumption will be gradually coordinated with the strengthening awareness of environment protection and increasing of economic income. A survey reveals that most consumers caring for environment hold positive attitude to environment-friendly hotels and they are willing to pay more for such hotel products[5]. Therefore, when low-carbon green products are first introduced to the market, their target customers are those caring for environment with certain consuming ability hence the price is a bit higher than same traditional products. Based on this, with the retrieving cost and income from energy innovation and energy efficiency, the price will be reduced so as to promote the products.

\section{Place Strategy of Hotel Green Marketing under Low- carbon Economy}

Low-carbon green channel is the key to implement lowcarbon green marketing successfully. From the traditional 
point of view, green place strategy demands the hotel should take first consideration of zero distance when choosing supplier or intermediate, i.e. choose local supplier or intermediate so as to reduce carbon release incurred by long-distance transportation. The low-carbon green credit of the supplier or the intermediate should be reviewed so as to purchase environment-friendly or recycled products. Lowcarbon green awareness of the supplier or the intermediate should be strengthened so as to build low-carbon green marketing net. At the same time, the hotel should take advantage of its unique status in food, accommodation, transport, travelling, purchasing and entertainment to improve the environment protection awareness of the supplier and demand the low-carbon green products and service from them. From the perspective of new marketing channel, the hotel should build its own reservation net actively. With the help of the distributor, the hotel can balance its pricing so as to reduce the cost and waste for a green channel. The advantages of building its own website include enterprise image propaganda, more clear and quick information receiver (amenities, environment, special service and price),customer demand and suggestion at the first time, interactivity so as to achieve the selling target of online reservation for old and new customers. With the global popularity of internet, the new channel of online distributor brings more benefits for the customers under low-carbon economy. The consumers in the data base of the online distributor are enormous, who cannot be touched depending on the hotel itself. When the distributor is achieving its self benefit, it also promotes the hotel brand with the help of its marketing platform so as to gap the deficiency of little brand propaganda[6]. The hotel cannot depend on the distributor, otherwise it will weaken its own pricing ability hence no green price for the benefit of the customer. The hotel should be mature enough in its direct selling system, which can ensure that the distributor is only a beneficial compliment under the circumstance of no marginal benefit improvement so as to balance channel pricing ability. The hotel manages to reduce distributors and channel organization by building its own online selling channel and with the help of complimentary selling of online distributor so as to reduce marketing cost and energy consumption and bring the benefit to the customers, which realizes the low-carbon green marketing in the real sense.

\section{Promotion Strategy of Hotel Green Marketing under Low-carbon Economy}

Promotion is the communication between companies and consumers. Promotion mix includes advertisement, business extension, public relations and personal selling. Under low-carbon economy suitable promotion mix are public relations and operation promotion. Public relations refer to the process of building enterprise positive image and cultivate consumer preference with the help of the third party so as to be beneficial to products selling. The hotel image has a direct impact on the operation and development of the hotel, which is the most important invisible and priceless asset. Although the good image of the hotel cannot create profit directly, it can open the market indirectly so as to bring good economic and social effect. The hotel can post low-carbon green logo of environment protection in the lobby, guest room, restaurant and gym centre. The hotel can arrange some special event to attract the attention to the hotel activity, e.g. low-carbon green food festival. Lowcarbon economy is a hot topic. The hotel can broadcast some non-profitable advertisement of low-carbon, which can be an effective policy. The hotel can build its green image with the help of microblog of some stars. The hotel should display its effort in the field of low-carbon and green marketing by good public relations so as to build a good image in the public. The effect of low-carbon promotion is closely related to the front-line staff members of the hotel, who should learn more low-carbon knowledge and strengthen environment-protection awareness. The hotel should set relevant rewards to improve their activity in promoting low-carbon products. The hotel should take some incentive measures to encourage ordinary guests to use lowcarbon service, e.g. reward some coupon or use some amenities free of charge.

In mobile era of Internet, the hotel should promote its green products through microblog, Wechat, LBS for interactivity. No matter it is microblg or other social media, the content should not only be focused on propaganda but on a topic for participation. Then the hotel could be interactive with the guests. It is a display of sincerity to communicate with the guests heartedly, promptly. Catch the guests by internet media, interact with the guests through microblog and Wechat so as to get the feedback and improve service for the guests. The hotel builds a community, in which the guests of a feather are identified on Internet. The hotel brand and culture drives the guests to flow together.

\section{V.CONCLUSION}

There is no denying that low-carbonization is not an endeavour for the hotel alone, nevertheless, if 4 Ps strategies of hotel green marketing under low-carbon economy can be implemented, then the future of hotel low-carbonization will be prospective.

\section{ACKNOWLEDGEMENTS}

The research work was supported by Jiangsu Education Department of China under Grant No. 2010SJD630015.

\begin{tabular}{l}
\multicolumn{4}{c}{ REFERENCES } \\
[1] Statistics and tourism satellite account[EB/OL], \\
Http://statistics.unwto.org
\end{tabular}

[2] C. Gonroos, Developing the service offering - a source of competitive advantage, American Marketing Association, P.83, 1983.

[3] Philip Kotler, Marketing for hospitality and tourism, Dongbei University of Finance \& Economics Press, 2010.

[4] Weiwei Ge. Luxury and responsibility. Harvard Business Review,(9), 2008

[5] Yi Zhao. Tourism marketing. Qinhua University Press, 2006.

[6] Yulei Cao. Hotel distributor: direct selling or distribution. Journal of sale and Market,(6),pp60-62, 2010. 